\title{
Severe fever with thrombocytopenia syndrome with re-infection in China: a case report
}

Shou-Ming Lv ${ }^{1,2+}$, Chun Yuan ${ }^{3 \dagger}$, Lan Zhang ${ }^{3 \dagger}$, Yu-Na Wang ${ }^{2}$, Zi-Niu Dai ${ }^{2,4}$, Tong Yang ${ }^{2}$, Ke Dai ${ }^{2}$, Xiao-Ai Zhang ${ }^{2}$, Qing-Bin Lu', Zhen-Dong Yang ${ }^{3}$, Ning $\mathrm{Cui}^{3}$, Hao Li ${ }^{1,2^{*}}$ and Wei Liu ${ }^{1,2,45^{*}}$ (D)

\begin{abstract}
Background: Severe fever with thrombocytopenia syndrome (SFTS), an emerging tickborne infectious disease caused by a novel banyangvirus (SFTS virus, SFTSV), was endemic in several Asian countries with a high mortality up to 30\%. Until recently, SFTSV-associated re-infection have not been reported and investigated.
\end{abstract}

Case presentation: A 42-year-old female patient was identified as a case of SFTS with re-infection, with two episodes of SFTSV infection on June 2018 and May 2020. The diagnosis of SFTS was confirmed by detection of SFTSV RNA in the blood samples using real-time reverse-transcription polymerase chain reaction and antibodies specific for SFTSV using enzyme linked immunosorbent assay. The changes of viremia and antibody response differed between the two episodes. Phylogenetic analysis showed the two viral genome sequences were in the same clade, but showing $0.6 \%$ dissimilarity of the nearly whole nucleotide sequence. Analysis of clinical data revealed that the second episode showed milder illness than that of the first episode.

Conclusions: Epidemiological and clinical findings, viral whole genomic sequences, and serological evidence, provided evidence for the re-infection of SFTSV rather than prolonged viral shedding or relapse of the original infection. The patients with re-infection of SFTSV may be at high odds of clinically inapparent or mildly symptomatic. More attention should be directed towards the long-term follow up of the recovered patients in the future, to explicitly acquire the decay profile of their immunity response.

Keywords: Severe fever with thrombocytopenia syndrome, Re-infection, Tick-borne infectious disease

\footnotetext{
*Correspondence: lihao_1986@126.com; Iwbime@163.com

†Shou-Ming LV, Chun Yuan and Lan Zhang contributed equally to this work.

${ }^{2}$ Beijing Institute of Microbiology and Epidemiology, State Key

Laboratory of Pathogen and Biosecurity, 20 Dong-Da Street, Fengtai District, Beijing 100071, People's Republic of China

Full list of author information is available at the end of the article
} permits use, sharing, adaptation, distribution and reproduction in any medium or format, as long as you give appropriate credit to the original author(s) and the source, provide a link to the Creative Commons licence, and indicate if changes were made. The images or other third party material in this article are included in the article's Creative Commons licence, unless indicated otherwise in a credit line to the material. If material is not included in the article's Creative Commons licence and your intended use is not permitted by statutory regulation or exceeds the permitted use, you will need to obtain permission directly from the copyright holder. To view a copy of this licence, visit http://creativecommons.org/licenses/by/4.0/. The Creative Commons Public Domain Dedication waiver (http://creativeco mmons.org/publicdomain/zero/1.0/) applies to the data made available in this article, unless otherwise stated in a credit line to the data. 


\section{Background}

Severe fever with thrombocytopenia syndrome (SFTS) is an emerging infectious disease caused by a novel phlebovirus (SFTS virus, SFTSV) in the family Phenuiviridae of the order Bunyavirales [1]. The disease was identified first in China in 2010 and subsequently in the Republic of Korea and Japan in 2012 [1-3]. So far, the number of SFTS cases has increased and the geographic distribution has expanded consistently, with the cumulative case numbers attaining 11995 in China by 2018, 866 in the Republic of Korea by 2018, and 467 in Japan by August 2019, according to the most recent updates [4]. The mortality rate of SFTS was high, up to $30 \%$ at early epidemic period [5]. There has been rare concern as to whether SFTS re-infection occurs, as studies have showed that most of the surviving patients developed neutralizing antibodies after infection of SFTSV [6, 7]. Even antibody titer declined in recovered patients, there is cellular and humoral immune memory that can be stimulated to protect the patient from re-infection [8].

Since the year of first report of SFTS, we have performed a prospective study on SFTS patients in one reference hospital in Xinyang [9], the most severely afflicted region by SFTS in China. All the SFTS patients who were re-entered into the hospital were picked and tested for their re-infection of SFTSV by performing real-time reverse-transcription polymerase chain reaction (RTPCR) [10]. Here, we describe the first case of re-infection of SFTSV (in a 42-year-old female) in China, and report the clinical and epidemiological findings, as well as characteristics of viral genomic sequences and antibody responses.

\section{Case presentation}

\section{Disease history and clinical examination}

The patient was a 42-year-old female farmer without underlying conditions residing in Xinyang city, Henan province of China. During the first episode in June 2018, she was admitted into the PLA 990 hospital with acute fever (temperature, up to $39.0{ }^{\circ} \mathrm{C}$ ), fatigue, nausea, and myalgia for five days. Before this disease, she had taken daily farming work in the field, but reported no history of tick bite during the past month. On admission, blood test determined the presence of leukocytosis [white blood cell (WBC) count, $1.3 \times 10^{9} / \mathrm{L}$ ] and thrombocytopenia [platelet (PLT) count, $67 \times 10^{9} / \mathrm{L}$; Table 1 ]. The diagnosis was confirmed by detection of SFTSV RNA in the blood samples using RT-PCR, and the viral genomic sequence was subsequently obtained. Her conditions during the hospitalization mimicked that of the general pattern from SFTSV infection, i.e., deteriorating shortly after admission, featured by newly developed vomiting (3 times per day), diarrhea (5-6 times per day), persistent decreasing of PLT counts, and increasing of serum alanine aminotransferase (ALT), aspartate aminotransferase (AST), lactate dehydrogenase (LDH), and creatine kinase (CK) levels. The worst situation was observed at 7-10 days after disease onset, and steadily resolve thereafter (Fig. 1). The patient was discharged from hospital at 15 days after disease onset, with all the clinical manifestations resolved and all laboratory abnormalities (except for elevated ALT and AST levels) returning to normal by then. The dynamic evaluation of SFTSV viremia during hospitalization revealed a similar pattern as those of other laboratory indicators, firstly evaluated as $8.8 \times 10^{4}$ copies $/ \mathrm{ml}$ on admission, increased to peaking level of $4.3 \times 10^{5}$ copies $/ \mathrm{ml}$ at day 7 after symptom onset, and

Table 1 Laboratory test results of the patient at twice episodes of SFTSV infection

\begin{tabular}{|c|c|c|c|c|c|}
\hline \multirow[t]{2}{*}{ Characteristics } & \multirow[t]{2}{*}{ Normal range } & \multicolumn{2}{|l|}{ First episode } & \multicolumn{2}{|c|}{ Second episode } \\
\hline & & On admission & $\begin{array}{l}\text { Peak or nadir during } \\
\text { hospitalization }\end{array}$ & On admission & $\begin{array}{l}\text { Peak or } \\
\text { nadir during } \\
\text { hospitalization }\end{array}$ \\
\hline White blood cell count, $\times 10^{9} / \mathrm{L}$ & $4.0-10.0$ & 1.3 & 1.3 & 1.3 & 1.3 \\
\hline Platelet count, $\times 10^{9} / \mathrm{L}$ & $100-300$ & 67 & 33 & 64 & 62 \\
\hline Lymphocyte percentage, \% & $20-40$ & 29.3 & 12.8 & 35.6 & 21.9 \\
\hline Neutrophil percentage, \% & $50-70$ & 64.6 & 84.6 & 58.5 & 72.7 \\
\hline Hemoglobin, g/L & $110-170$ & 120 & 103 & 98 & 96 \\
\hline Alanine aminotransferase, $\mathrm{U} / \mathrm{L}$ & $0-40$ & 22 & 185 & 229 & 292 \\
\hline Aspartate aminotransferase, U/L & $0-40$ & 39 & 332 & 487 & 585 \\
\hline Lactate dehydrogenase, U/L & $109-245$ & 190 & 473 & 688 & 688 \\
\hline Creatine kinase, U/L & $25-200$ & 154 & 510 & 363 & 390 \\
\hline Albumin, g/L & $35-55$ & 46.1 & 34.1 & 34.7 & 34.7 \\
\hline Potassium, mmol/L & $3.5-5.5$ & 2.63 & 2.63 & 3.55 & 3.55 \\
\hline
\end{tabular}



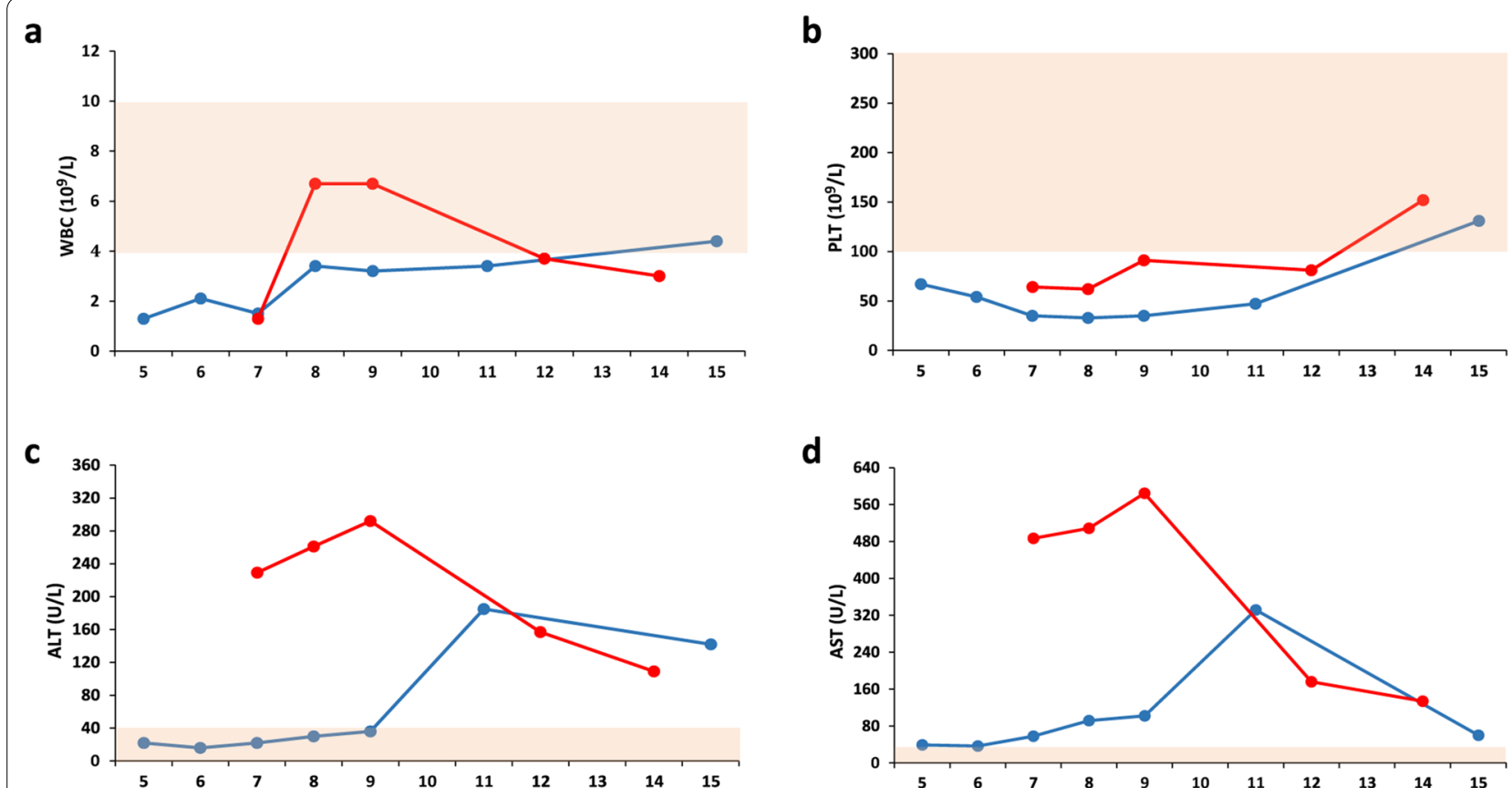

d

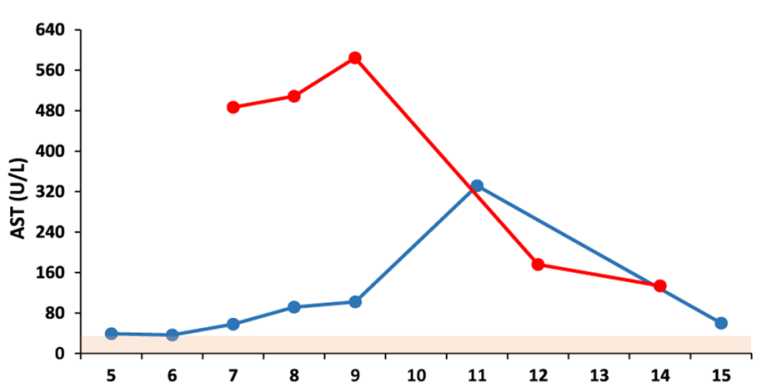

e

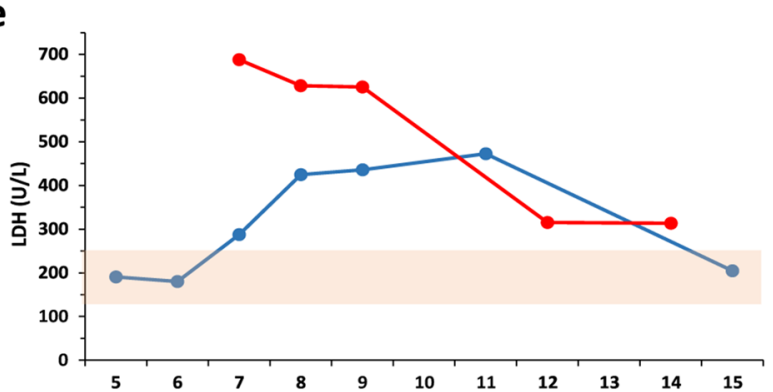

f

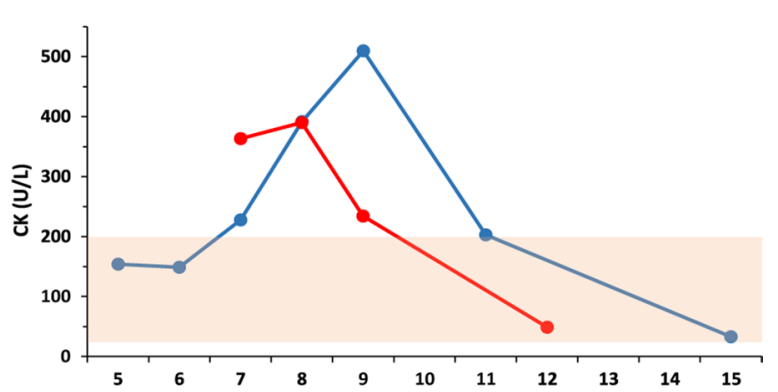

g

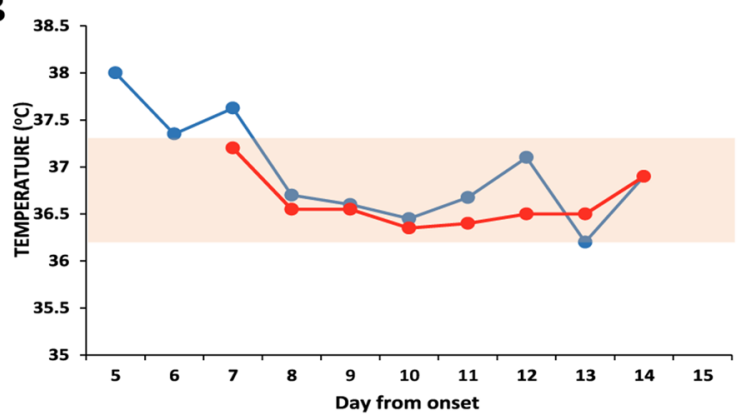

h

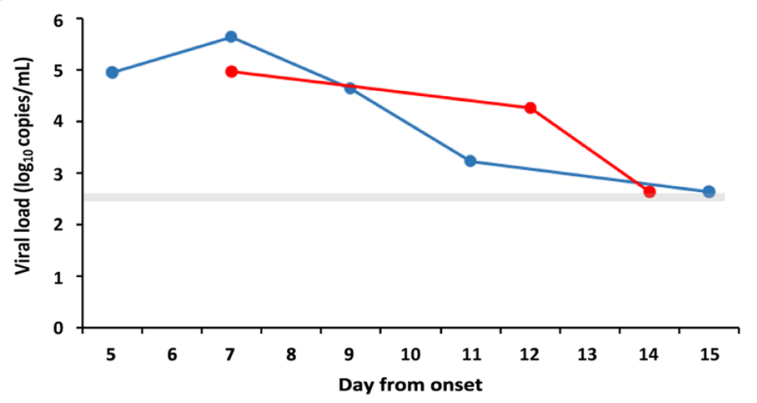

- 1st admission - 2nd admission Normal range

Fig. 1 Dynamics of laboratory indicators for two episodes of SFTSV infection from the same patient. a White blood cell (WBC) count; b Platelet (PLT) count; c Alanine aminotransferase (ALT); d Aspartate aminotransferase (AST); e Lactate dehydrogenase (LDH); $\mathbf{f}$ Creatine kinase (CK); $\mathbf{g}$ Body temperature; $\mathbf{h}$ Viral load were shown. The orange area indicates the normal range; the gray line indicates the detection limit of SFTSV RNA

then reduced to $4.3 \times 10^{4}$ copies $/ \mathrm{ml}, 1.7 \times 10^{3}$ copies/ $\mathrm{ml}$ at days 9 and 11, respectively (Fig. 1). Viral clearance occurred on day 15 after symptom onset, verified by two consecutive negative RT-PCR tests for SFTSV. The treatment included antiviral therapy with favipiravir and supportive treatment including supplement of 
electrolytes and dextrose, antipyretics, hepatoprotective, stomach protection, antiemetics, anti-inflammatory, and anticoagulants.

Her second episode of SFTS developed on May 20, 2020, when the patient was re-admitted into the same hospital due to the symptom of fever (highest temperature $37.8{ }^{\circ} \mathrm{C}$ ) for 7 days, accompanied by milder clinical manifestations than that of the first episode, such as lower temperature, no vomiting or diarrhea. Again, no tick bite was reported. The dynamic evaluation of laboratory indicators revealed milder thrombocytopenia than the first episode (nadir counts $62 \times 10^{9} / \mathrm{L}$ vs $33 \times 10^{9} / \mathrm{L}$ ). In contrast, serum levels of ALT, AST, and LDH, were observed with higher peaking levels during the second episode (Table 1). Her temperature returned to normal on day 7 and the physical abnormalities largely resolved on day 14 after symptom onset. The peaking SFTSV viremia appeared lower than that of the first episode, with the viral load estimated as $9.5 \times 10^{4}$ copies $/ \mathrm{ml}$ at 7 days post disease, decreased to $4.3 \times 10^{4}$ copies $/ \mathrm{ml}$ on day 12 , and to an undetectable level on day 14 after symptom onset (Fig. 1). Similar therapy regimens were administered as the first episode, except for no favipiravir was administered.

\section{Antibody response}

The serum specimens collected at 7, 9, 11, 15 days after symptom onset for the first episode and $7,12,14$ days after symptom onset for the second episode were tested for IgM and IgG antibodies against SFTSV using enzyme linked immunosorbent assay (ELISA) kit (Wen Ding BioTech Co., Ltd, Nanjing, China). It's notable that the SFTSV specific IgG antibody remained negative during the hospitalization for the first episode, while was produced at 14 days post disease for the second episode to titer of 1:80. In parallel, IgM turned positive at 9 days post disease for the first episode, while tested to be positive at 7 days with titer of 1:80 for the second episode (Additional file 1: Table S1).

\section{Virus molecular characterization}

Whole genome sequencing was performed on two samples that were collected before antiviral therapy from two episodes respectively. Phylogenetic analysis based on nucleotide sequences of L (GenBank accession numbers:
MW021165 and MW021168), M (MW021166 and MW021169), or S (MW021167 and MW021170) segments [11], showed that the two viral genome sequences were in the same clade, most closely related to strains identified in Xinyang (Fig. 2). The two virus genomes differ by 72 nucleotides, with 38,21 , and 13 in the L, M, S segments, respectively. Nine different amino acids were identified between the two genomes, including 4 in the RNA-dependent RNA polymerase (RdRp), 2 in glycoprotein precursor (GP), 1 in nucleocapsid protein (NP), and 2 in nonstructural protein (NS).

\section{Discussion and conclusions}

Previous reports have raised questions around the possibility of re-infection with highly lethal viruses such Ebola virus and Lassa virus $[12,13]$, however, fewer confirmed cases have been reported. In the current study, we reported a case of re-infection with SFTSV, which was supported by epidemiological and clinical findings, as well as whole genomic sequences and serological evidence, rather than prolonged viral shedding or relapse of the original infection. First, whole genome analysis revealed 72 nucleotide differences between the SFSTV strains determined from two episodes. Both were phylogenetically close to the locally circulating strains, fully reflective of the infectious source of this patient. Second, the patient was discharged from hospital only after two consecutive negative detection for SFTSV. Although no examination was performed during the interval between two episodes, persistent existence of SFTSV over two years is impossible. Third, the patient had relatively high viral load with gradual decline for both episodes, and seroconversion of SFTSV IgG during the first episode was lower than the average level which had been derived from other patients treated in the same hospital [14], highly likely related to the second episode of re-infection.

The mutation of the second strains was unlikely to evade the protection elicited from the first infection. Therefore, the comprised immunity to SFTSV that was acquired from the first infection might render the patients succumb to the re-infection, however, no samples were collected during the interval between two episodes, thus no measurement of antibody was available to determine to what extent the antibody had been waned

(See figure on next page.)

Fig. 2 Phylogenetic analysis based on nucleotide sequences of SFTSV. a Nearly full-length of the L segments (6258 bp); b M segments (3335 bp); c S segments (1689 bp) of SFTSV were used for construction of phylogenetic trees. The Maximum Likehood method with the best substitution model (Tamura 3-parameter + G) was conducted using MEGA version 5.0 (http://www.megasoftware.net). Bootstrap analysis of 1000 replicates was applied to assess the reliability of the reconstructed phylogenies. Scale bars indicate estimated evolutionary distance. The strain name of SFTSV was specified. The bold indicates the two SFTSV strains in the study 


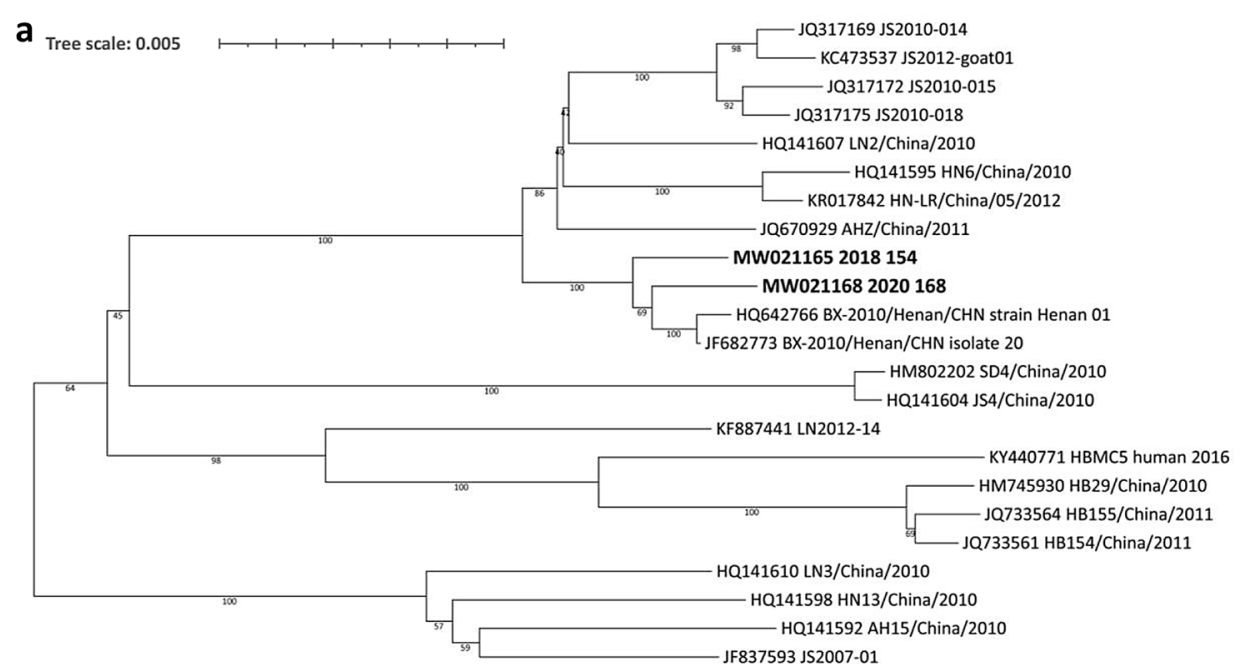

b

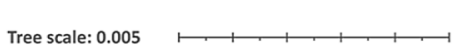

JQ317170 JS2010-014

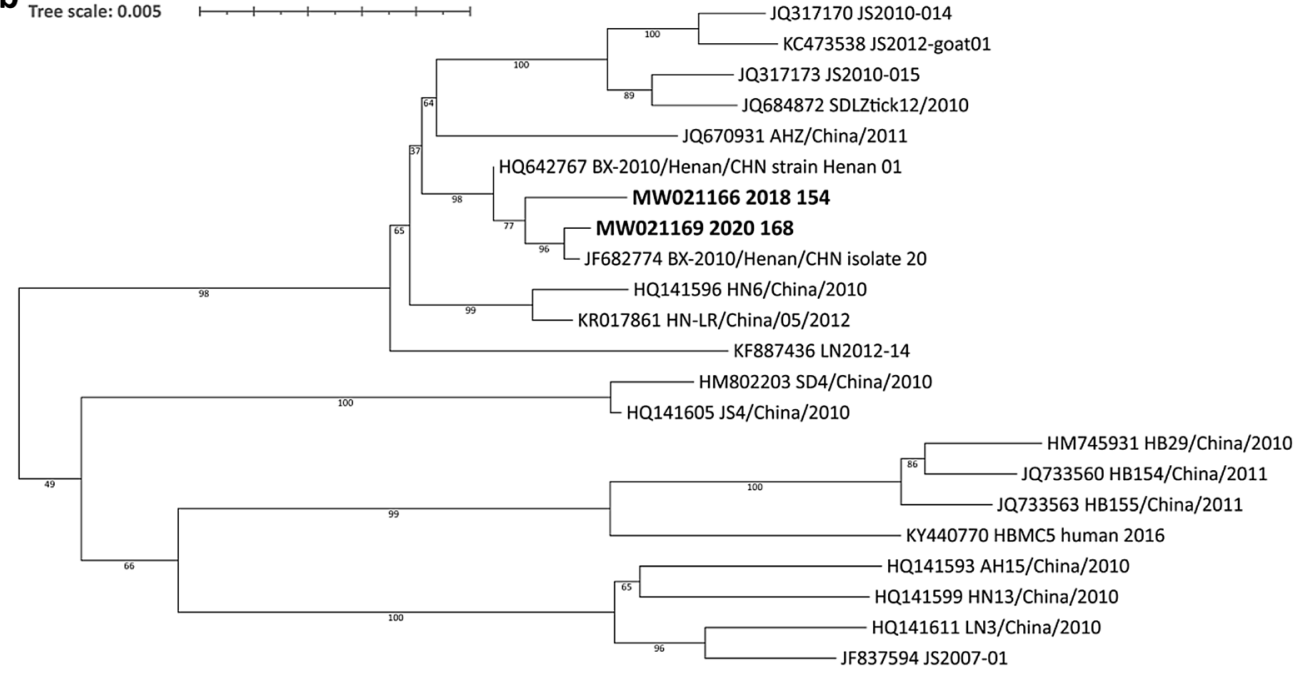

C Tree scale: 0.005

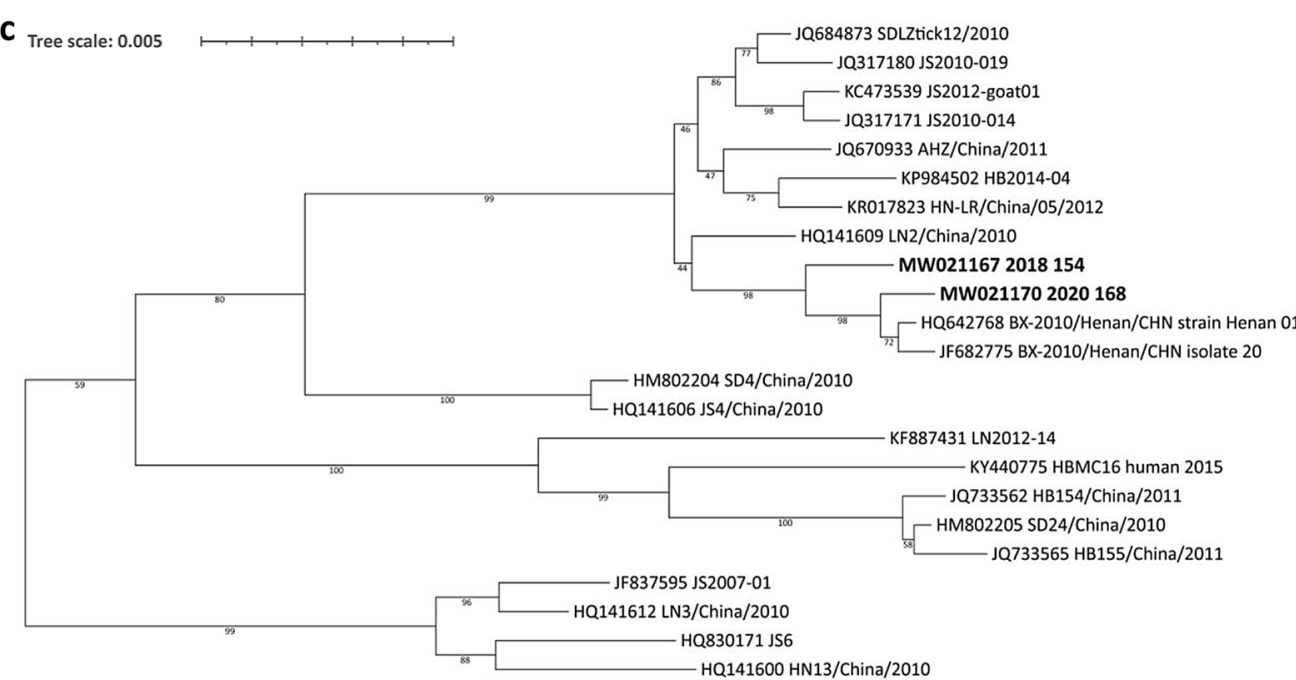

Fig. 2 (See legend on previous page.) 
or whether there was immune memory to be stimulated upon re-exposure to the virus.

Based on this finding, we suggest that although occurring with rare occasion, host immunity acquired following primary SFTSV infection might fail to protect patients from re-infection after subsequent exposure to the virus. The second visit of this patient showed milder clinical manifestations and lower viremia, yet higher serum levels of ALT, AST, and LDH, in comparison with the first episode, which phenomenon is beyond expectation. However, the AST/ALT ratio that has been considered as a better indicator of the type of liver injury than changes in AST or ALT alone [15], was higher in the first episode (Additional file 1: Fig. S1). No antibody dependent enhancement (ADE) had ever been reported for SFTSV or any other members in the same family, and we assume this case presented here represent only the untypical clinically apparent infections which presented to health care facilities. In case of re-infection, the patients are at high odds of clinically inapparent or mildly symptomatic. Thus, more attention should be directed towards the long-term follow up of the recovered patients in the future, to explicitly acquire the decay profile of their immunity response.

The current finding has implication that in case of vaccine development, vaccines may not be able to provide lifelong protection against SFTSV, as infection might occur despite a static level of specific antibodies. Still more isolation and cross protection assay is warranted to determine whether these amino acid differences in the $\mathrm{G}$ protein defined between two episodes is responsible for the re-infection.

\section{Abbreviations}

SFTS: Severe fever with thrombocytopenia syndrome; SFTSV: Severe fever with thrombocytopenia syndrome virus; RT-PCR: Real-time reverse-transcription polymerase chain reaction; ELISA: Enzyme linked immunosorbent assay; WBC: White blood cell; ALT: Alanine aminotransferase; AST: Aspartate aminotransferase; LDH: Lactate dehydrogenase; CK: Creatine kinase; RdRp: RNA-dependent RNA polymerase; GP: Glycoprotein precursor; NP: Nucleocapsid protein; NS: Nonstructural protein; ADE: Antibody dependent enhancement.

\section{Supplementary Information}

The online version contains supplementary material available at https://doi. org/10.1186/s40249-021-00877-6.

Additional file 1: Table S1. The titers of SFTSV specific lgM and IgG antibodies for two episodes of SFTSV infection from the same patient. Fig. S1. Dynamic ratio of aspartate aminotransferase and alanine aminotransferases for two episodes of SFTSV infection from the same patient.

Acknowledgements

Not applicable.
Authors' contributions

WL and $H L$ contributed to the study design and the manuscript preparation. $H L, S L, Y W, Z D, X Z$, and QL contributed to data analysis. CY, LZ, ZY, and NC contributed to the collection of clinical specimens and information. SL, TY, and $\mathrm{KD}$ contributed to in vitro experiments. All authors read and approved the final manuscript.

\section{Funding}

This study was supported by the Natural Science Foundation of China (81825019 and 81722041), the China Mega-project for Infectious Diseases (2018ZX10713002 and 2018ZX10101003-002), and the National Key Research and Development Program of China (2018YFE0200401).

Availability of data and materials

Not applicable.

\section{Declarations}

\section{Ethics approval and consent to participate}

The research protocol was approved by the human ethics committee of the PLA 990 hospital in accordance with the medical research regulations of China and the committee's reference number is [154YY-LL-2018-03].

\section{Consent for publication}

Written informed consent was obtained from the patient for this publication.

\section{Competing interests}

None of the authors have conflicts of interest to report.

\section{Author details}

${ }^{1}$ Graduate School of Anhui Medical University, Hefei 230032, People's Republic of China. ${ }^{2}$ Beijing Institute of Microbiology and Epidemiology, State Key Laboratory of Pathogen and Biosecurity, 20 Dong-Da Street, Fengtai District, Beijing 100071, People's Republic of China. ${ }^{3}$ The 990 Hospital, People's Liberation Army, Xinyang 464000, People's Republic of China. ${ }^{4}$ College of Life Sciences, Fujian Agriculture and Forestry University, Fuzhou 350002, People's Republic of China. ${ }^{5}$ School of Public Health, Peking University, Beijing 100191, People's Republic of China.

Received: 10 May 2021 Accepted: 22 June 2021

Published online: 29 June 2021

\section{References}

1. Yu XJ, Liang MF, Zhang SY, Liu Y, Li JD, Sun YL, et al. Fever with thrombocytopenia associated with a novel bunyavirus in China. N Engl J Med. 2011;364:1523-32.

2. Kim K, Yi J, Kim G, Choi S, Jun K, Kim N, et al. Severe fever with thrombocytopenia syndrome, South Korea, 2012. Emerg Infect Dis. 2013;19:1892-4.

3. Kobayashi Y, Kato H, Yamagishi T, Shimada T, Matsui T, Yoshikawa T, et al. Severe fever with thrombocytopenia syndrome, Japan, 2013-2017. Emerg Infect Dis. 2020;26:692-9.

4. Miao D, Liu MJ, Wang YX, Ren X, Lu QB, Zhao GP, et al. Epidemiology and ecology of severe fever with thrombocytopenia syndrome in China, 2010-2018. Clin Infect Dis. 2020;ciaa1561.

5. Liu Q, He B, Huang SY, Wei F, Zhu XQ. Severe fever with thrombocytopenia syndrome, an emerging tick-borne zoonosis. Lancet Infect Dis. 2014;14:763-72.

6. Huang YT, Zhao L, Wen HL, Yang Y, Yu H, Yu XJ. Neutralizing antibodies to severe fever with thrombocytopenia syndrome virus 4 years after hospitalization, China. Emerg Infect Dis. 2016;22:1985-7.

7. Li DX, Shao LJ, Bi Y, Niu GY. Neutralizing antibodies to severe fever with thrombocytopenia syndrome virus in general population, Shandong province, China. Sci Rep. 2018;8:15401. 
8. Song PX, Zheng N, Liu Y, Tian C, Wu XL, Ma XH, et al. Deficient humora responses and disrupted B-cell immunity are associated with fatal SFTSV infection. Nat Commun. 2018;9:3328.

9. Li H, Lu QB, Xing B, Zhang SF, Liu K, Du J, et al. Epidemiological and clinical features of laboratory-diagnosed severe fever with thrombocytopenia syndrome in China, 2011-17: a prospective observational study. Lancet Infect Dis. 2018;18(10):1127-37.

10. Li H, Zhang LK, Li SF, Zhang SF, Wan WW, Zhang YL, et al. Calcium channel blockers reduce severe fever with thrombocytopenia syndrome virus (SFTSV) related fatality. Cell Res. 2019;29:739-53.

11. Liu W, Lu QB, Cui N, Li H, Wang LY, Liu K, et al. Case-fatality ratio and effectiveness of ribavirin therapy among hospitalized patients in China who had severe fever with thrombocytopenia syndrome. Clin Infect Dis. 2013;57(9):1292-9.
12. Maclntyre CR, Chughtai AA. Recurrence and reinfection-a new paradigm for the management of Ebola virus disease. Int J Infect Dis. 2016:43:58-61.

13. Lukashevich LS. Advanced vaccine candidates for Lassa fever. Viruses. 2012:4:2514-57.

14. Lu QB, Cui N, Hu JG, Chen WW, Xu W, Li H, et al. Characterization of immunological responses in patients with severe fever with thrombocytopenia syndrome: a cohort study in China. Vaccine. 2015;33:1250-5.

15. Fontana RJ, Lok AS. Noninvasive monitoring of patients with chronic hepatitis C. Hepatology. 2002;36(5 Suppl 1):S57-64.
Ready to submit your research? Choose BMC and benefit from:

- fast, convenient online submission

- thorough peer review by experienced researchers in your field

- rapid publication on acceptance

- support for research data, including large and complex data types

- gold Open Access which fosters wider collaboration and increased citations

- maximum visibility for your research: over $100 \mathrm{M}$ website views per year

At BMC, research is always in progress.

Learn more biomedcentral.com/submissions 